\title{
DO TERMOSCÓPIO AO TERMÔMETRO DIGITAL: QUATRO SÉCULOS DE TERMOMETRIA
}

\section{Denise Prazeres Lopes Pires e Júlio Carlos Afonso*}

Departamento de Química Analítica, Instituto de Química, Universidade Federal do Rio de Janeiro, CT, Bloco A, CP 68563, 21949-900 Rio de Janeiro - RJ, Brasil

\section{Francisco Artur Braun Chaves}

Departamento de Física da Matéria Condensada, Instituto de Física, Universidade Federal do Rio de Janeiro, CT, Bloco A, CP 68528, 21941-972 Rio de Janeiro - RJ, Brasil

Recebido em 14/6/05; aceito em 3/11/05; publicado na web em 14/6/06

\begin{abstract}
FROM THE THERMOSCOPE TO THE DIGITAL THERMOMETER: FOUR CENTURIES OF THERMOMETRY. This work describes the evolution of temperature measurement in the last four centuries using thermometers based on the thermal expansion of liquids such as ethyl alcohol and mercury. The concept of temperature was strongly dependent on the researcher and there was no systematic temperature scale for universal use. The precursor of the common thermometer was the thermoscope, probably invented at the end of the XVIth century. In the XVIIIth century the instrument was greatly improved and several thermometric scales were proposed some of which have been in use until now. These scales were based on arbitrary points. Mercury and ethyl alcohol were the most employed thermometric fluids. In the XIXth century, the concept of absolute zero was a great advance in this field. The most important contribution during the XXth century was the establishment of international temperature scales. The design of the thermometer has been essentially the same along the last 300 years, but many models were proposed for industrial and research purposes. Its association with the densimeter was of great importance for control of industrial chemical processes and also for teaching purposes in the past. Nowadays, there is a clear tendency to replace mercury-based thermometers by electronic digital models. Thermochemistry is the natural relationship between temperature and chemistry.
\end{abstract}

Keywords: thermometry; thermometer; thermochemistry.

\section{NOÇÃO INTUITIVA DE TEMPERATURA}

Quando se coloca uma vasilha com água líquida sobre uma chama, como a de um bico de gás, observa-se que o líquido esquenta até, eventualmente, ferver. Por outro lado, se forem adicionados blocos de gelo à água, esta irá esfriar.

Nessas situações observa-se a presença de corpos quentes (a chama) e frios (o gelo). Isso leva à introdução de dois termos associados entre si, quente e frio, o que leva a uma noção subjetiva de temperatura, baseada no sentido do tato. Se é dito que um corpo está quente, esta afirmação tem de estar necessariamente relacionada à temperatura de um outro corpo mais frio. A temperatura é uma grandeza que depende da comparação direta do estado em que se encontram dois ou mais corpos ${ }^{1}$.

Quando dois objetos são postos em contato (diz-se que estão em contato térmico), o objeto com temperatura maior esfria, enquanto que o objeto com temperatura menor esquenta. Isso se dá mediante a transferência de energia entre os corpos, do mais quente para o mais frio. Existem duas leis empíricas que tratam desse assunto ${ }^{2,3}$ : Lei de Prévost (1751-1839) - Entre dois corpos desigualmente aquecidos, há uma constante troca de calor em intensidades diferentes, de modo que o corpo quente emite mais calor do que recebe, resfriando-se em consequiência, e o corpo frio recebe mais calor do que emite, aquecendose, e Lei de Newton (1642-1727) - O resfriamento de um corpo é tanto maior quanto mais quente ele estiver em relação ao meio onde se encontra. A energia em trânsito de um corpo para outro é denominada calor $^{4}$. A idéia de que o calor era uma forma de energia (no caso, energia térmica) só foi estabelecida na Física no século XIX, ocasião em que o calor era tido como uma substância que se incorporava nos

*e-mail: julio@iq.ufrj.br corpos ou sistemas materiais (o "calórico"). James P. Joule (18181889) foi um dos que contribuíram significativamente para se estabelecer a "equivalência de forças".

A parte da Física que estuda o calor é a Termologia. O termo termometria é reservado ao estudo dos processos de medição de temperatura dos $\operatorname{corpos}^{1,2,4}$. Sob o ponto de vista macroscópico ${ }^{1}$, a noção de temperatura é sugerida a partir dos sentidos, enquanto que o aspecto microscópico é dado ao se considerar o movimento molecular associado ao aquecimento/resfriamento. A temperatura pode, então, ser entendida como sendo a medida do grau de agitação (movimento térmico) das moléculas do corpo considerado ${ }^{1,2,4}$.

\section{A NECESSIDADE DO TERMÔMETRO}

Através de seus sentidos o homem trava contato com o mundo físico que o cerca. A primeira noção de temperatura de um sistema é estabelecida a partir da sensação térmica que o tato proporciona, traduzida pelos termos frio, quente, gelado, etc. No entanto, para fins científicos, o critério "sensitivo" para avaliação das temperaturas é vago e impreciso, pois depende da pessoa e das condições nas quais a mesma se encontrava anteriormente. O corpo humano não é um bom "termômetro", pois além de ser um instrumento "diferencial" (uma vez que só consegue distinguir entre "mais frio" e "mais quente" em relação à sua própria temperatura) induz facilmente o observador em erro, dado que é sensível a outras grandezas, como, por ex., a condutividade térmica ${ }^{5}$ (uma maçaneta metálica "parece mais fria" ao tato que a madeira da porta onde se encontra, apesar de estarem ambas à mesma temperatura!).

Daí a necessidade de se estabelecer um instrumento padronizado de medida de temperatura que independa do sentido do tato. Chama-se termômetro o instrumento para medir a temperatura dos cor- 
pos. Ele faz uso de comparações entre a variação de propriedades das substâncias, como volume, pressão, resistência elétrica, variação de cor, etc. para relacioná-las com a variação de temperatura ${ }^{1-4}$.

Embora se trate de uma grandeza fortemente inserida no cotidiano, a temperatura apresenta alguns aspectos que a fazem um caso peculiar entre as grandezas físicas. Basta pensar, por ex., que, se forem unidos dois pedaços de metal com $1 \mathrm{~m}$ de comprimento cada, o comprimento total resultante será de $2 \mathrm{~m}$; já o mesmo não se passa ao juntar dois corpos encontrando-se cada um deles inicialmente à temperatura de $10{ }^{\circ} \mathrm{C}$, pois não passaremos a ter um corpo a $20{ }^{\circ} \mathrm{C}$, mas sim a $10^{\circ} \mathrm{C}$ (a temperatura é uma propriedade intensiva) ${ }^{6}$.

\section{PRINCÍPIOS GERAIS DE UMA ESCALA TERMOMÉTRICA}

A maneira mais fácil de estabelecer uma escala termométrica é achar uma substância que possua uma propriedade que se modifique de modo regular com a temperatura e tenha praticidade de uso. Por ex., o comprimento de uma barra aumenta (dilatação) quando esta se torna mais quente. A temperatura $t$ da barra é avaliada indiretamente pelo valor assumido pelo comprimento $L$.

Sendo $x$ uma grandeza conveniente que define uma das propriedades do corpo (no caso acima, $x=L$ ), a cada valor de $x$ faz-se corresponder um determinado valor $t$ de temperatura. Ao aquecer um corpo, sempre ocorrem concomitantemente três dilatações: a linear, a superficial e a volumétrica. No caso da barra, o comprimento é a dimensão preponderante, de modo que a dilatação linear é a relevante neste caso.

A grandeza $x$ é denominada grandeza termométrica. A correspondência entre os valores da grandeza $x$ e da temperatura $t$ constitui a função termométrica. A utilização do termômetro para avaliação da temperatura de um sistema fundamenta-se no fato de que, após algum tempo em contato, o sistema e o termômetro alcançam o equilíbrio térmico ${ }^{1,2,5}$.

Existem vários tipos de termômetros que diferem um do outro pela grandeza termométrica. Nos termômetros de líquido (assunto deste trabalho), como os de mercúrio e de álcool, a grandeza termométrica é o volume do líquido que, ao variar, muda a altura da coluna líquida. Nos termômetros de gás, a grandeza termométrica é o volume do gás (se a pressão permanece constante) ou a pressão do gás (quando o volume é constante). No termômetro de resistência de platina, a grandeza termométrica é a resistência elétrica de um fio desse metal.

O modelo mais comum é o termômetro de mercúrio (Figura 1). A expansão térmica deste metal é uniforme, prestando-se bem para medidas de temperatura entre $-30 \mathrm{e}+320^{\circ} \mathrm{C}$. Ele não adere ao vidro e sua aparência metálica facilita a leitura. $\mathrm{O}$ álcool etílico é usado para medições de temperaturas baixas, onde o mercúrio congela $\left(-38,9^{\circ} \mathrm{C}\right)$. Corantes costumam ser adicionados para visualizar a leitura $^{2,3,5}$, visto que o álcool etílico é incolor. Ao bulbo que contém o líquido, adapta-se uma haste de pequeno diâmetro (capilar). Esse pequeno diâmetro visa destacar a dilatação ou a contração da substância, aumentando a precisão da leitura ${ }^{1,2,5}$. Apesar dos líquidos não terem forma própria e estarem contidos em recipientes sólidos, o que obriga apenas ao estudo de sua dilatação volumétrica, esta, sob as condições de construção do termômetro, pode se processar de forma uniforme, desde que respeitados os limites das temperaturas de fusão e de ebulição da substância ${ }^{7,8}$.

O tubo capilar é feito de vidro capaz de resistir ao intervalo de temperatura em que o termômetro será utilizado e deve ser livre de quaisquer rugosidades e irregularidades internas, o que comprometeria a precisão do instrumento ${ }^{2,9}$. Além disso, não deve ser quimicamente reativo com o líquido. Para reduzir ainda mais a dilatação do vidro, emprega-se material que tenha sofrido processo de recozimento $^{7,8}$. O tubo deve ter em toda parte o mesmo diâmetro interno, a fim de que as divisões iguais da escala correspondam a iguais variações de temperatura, ou seja, a leitura seja linear ${ }^{5,8,9}$. O bulbo deve conter volume de líquido capaz de preencher toda a escala de leitura do instrumento ${ }^{5,7.8}$. No enchimento do termômetro de mercúrio, adapta-se um funil no topo da coluna e aquece-se o reservatório (bulbo) para dilatar o ar, tornando-o rarefeito; coloca-se então o metal no funil e resfria-se o bulbo. $\mathrm{O}$ ar contrai-se e puxa o mercúrio para dentro. Repete-se esta operação até o enchimento do bulbo e da parte inferior do tubo. Para que a dilatação do líquido seja uniforme, o ar deve ser expulso do interior do tubo capilar. Para tal, aquece-se o mercúrio contido no bulbo até que o tubo fique cheio por completo de líquido; separa-se o funil e fecha-se o topo do instrumento a fogo (solda). Ao resfriar, faz-se vácuo acima da coluna do mercúrio. Para líquidos como o álcool, deixa-se um pouco de ar para evitar a fragmentação da coluna líquida quando do resfriamento.

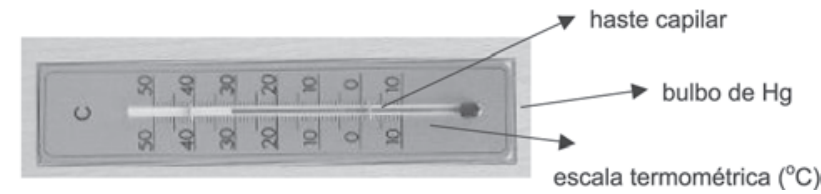

Figura 1. Termômetro comum (escala Celsius) evidenciando o líquido inserido no bulbo e na haste capilar.

Na construção do termômetro, a sensibilidade é parâmetro crucial e pode ser entendida sob dois pontos de vista ${ }^{10,11}$ : a) a rapidez de resposta do instrumento às variações de temperatura, e b) a capacidade de distinguir pequenas variações de temperatura. No caso (a), o termômetro possui reservatório com pequena quantidade de líquido, o que permite estabelecer o equilíbrio mais rapidamente; na situação (b), aumenta-se o espaçamento entre as frações de grau da escala termométrica, o que exige maiores massas de líquido ou então limita-se o seu funcionamento a uma faixa de temperatura estreita, como é o caso do familiar termômetro clínico.

A rigor, os termômetros de dilatação de líquidos baseiam-se na lei de expansão volumétrica do líquido com a temperatura dentro de um recipiente fechado ${ }^{1,5}$. A relação não é linear, mas para diferenças de temperaturas pequenas, a função termométrica se reduz a uma forma linear do tipo:

$t(x)=a x+b$

onde $t$ é a temperatura da substância utilizada e que muda com a propriedade $x$ da substância. As constantes a e b dependem da substância utilizada e podem ser calculadas especificando-se dois pontos na escala de temperatura (pontos fixos), como a fusão do gelo e a ebulição da água. $\mathrm{O}$ intervalo delimitado entre as marcações feitas para cada ponto fixo é dividido em partes iguais. Cada uma das partes desse intervalo é a unidade (o grau) da escala.

Os valores atribuídos à temperatura de um sistema qualquer dependem das escalas usadas, mesmo quando elas estão baseadas nos mesmos pontos de referência ${ }^{2,3}$. A rigor, o número que indica a temperatura é um valor arbitrário definido quando do estabelecimento da escala, e não uma medida absoluta. Um corpo a $30^{\circ} \mathrm{C}$ tem uma temperatura maior que um outro a $10^{\circ} \mathrm{C}$, mais isso não significa que o primeiro corpo seja três vezes "mais quente" que o segundo.

\section{A EVOLUÇÃO DA MEDIÇÃO DA TEMPERATURA}

\section{Primórdios}

A história da medição da temperatura é um pouco obscura. Os registros históricos situam a primeira tentativa de estabelecer uma 
"escala de temperaturas" no século II a.C., altura em que Galeno médico grego - teria sugerido que as sensações de "quente" e "frio" fossem medidas com base em uma escala com quatro divisões numeradas acima e abaixo de um ponto neutro; para tal escala termométrica, atribuiu a temperatura de "4 graus de calor" à água fervente, a temperatura de "4 graus de frio" ao gelo e a temperatura "neutra" à mistura de quantidades iguais daquelas duas substâncias"2.

Cerca de 1300 anos mais tarde, um outro "físico" (designação então dada aos médicos), Harme de Berna, criou uma escala de temperaturas baseada nas latitudes terrestres, atribuindo "4 graus de frio" aos pólos e "4 graus de calor" ao equador. De acordo com essa escala, seria possível estabelecer a mistura ideal de drogas a ministrar, de acordo com o local da Terra em que o paciente se encontrasse $e^{2,3,5}$.

A invenção do termoscópio, termômetro cujo princípio físico era a expansão do ar $^{2,3,7,8,11}$, tem um papel importante no desenvolvimento da termologia ${ }^{2}$. Talvez as primeiras medições de temperatura com alguma precisão, de que se tem conhecimento, tenham sido realizadas por Galileu Galilei (1564-1642), em 1592. Sua "escala" estava dividida em "graus de calor", segundo seus registros. Não se deve considerar esta menção como absoluta, pois Sanctorius Santori da Capodistria (1561-1636), Cornelius van Drebbell (15721634), Robert Fludd (1574-1637), Giambalista Porta (1538-1615), dentre outros estudiosos, também são apontados como idealizadores do primeiro protótipo daquilo que se chama hoje de termômetro ${ }^{2,3,7}$.

Porta, em 1606, descreveu em detalhes o termoscópio cujo esquema está na Figura $2^{2,3}$. Este instrumento consiste de um bulbo contendo um tubo longo com um extremo mergulhado em um líquido (água, álcool - posteriormente o vinho passou a ser muito utilizado). Um pouco do ar no tubo era expulso antes de se colocar o líquido. Isto fazia com que este subisse no tubo. Quando o ar restante no tubo e no bulbo era aquecido ou esfriado, o nível do líquido no tubo variava, refletindo a mudança na temperatura do ar. Uma escala no tubo permitia que a medida quantitativa dessas flutuações fosse feita. Um grave defeito deste aparelho é sua sensibilidade à variação da pressão atmosférica no local onde ele se encontrava, pois era um instrumento aberto ao meio exterior. Além disso, o líquido (sensor termométrico) evaporava-se com o tempo, tornando as leituras ainda mais inexatas e não reprodutíveis ${ }^{3,5,8}$.

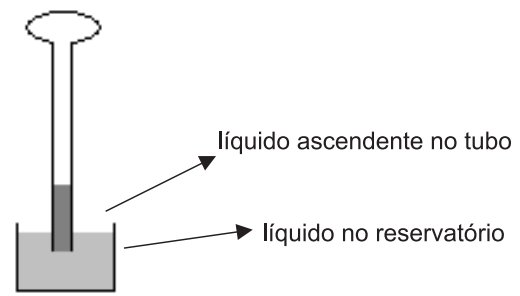

Figura 2. Princípio esquemático do termoscópio empregado no início do século XVII

Giovan F. Sagredó (1571-1620), em 1615, descreveu um modelo munido de escala graduada e de mistura refrigerante de neve e sal $^{2}$. van Helmont (1577-1644), em sua obra póstuma Ortus Medicinale (1648), descreveu um outro modelo, também propriamente transição entre o termoscópio e o termômetro. Robert Boyle (1627-1691) propôs o ponto de fusão do gelo como ponto fixo ${ }^{5,7,8}$.

O desenvolvimento seguinte teve lugar em Florença, na chamada Academia Dei Cimento (1657-1667). O líquido de enchimento era preferencialmente o álcool, por se dilatar mais que o mercúrio, também aparentemente testado ${ }^{2,8}$. A descrição dos termômetros feitos mostra que o formato era idêntico aos de hoje. Eram fechados (ao contrário dos termoscópios), mas o ar interior não era expulso antes da selagem do tubo, o que impedia a dilatação uniforme do líquido. Porém, ao selar o tubo, a influência da pressão atmosférica sobre a medida desaparecia. Esse aspecto foi um avanço importante na evolução do instrumento. Aparentemente, os pontos fixos eram as temperaturas do inverno e verão florentinos.

Em 1688, Joachin Dalence (1640-1707) foi o primeiro a afirmar que eram precisos dois pontos fixos para se determinar uma escala $^{2,5}$. Com base no termômetro a álcool, estabeleceu como pontos fixos o ponto de fusão do gelo e o da manteiga! Em 1694, Renaldini (1615-1698) trocou o ponto de fusão desta pelo de ebulição da água, já que Robert Hooke (1635-1703) demonstrara antes que, durante a fusão do gelo e a ebulição da água, a temperatura se mantinha constante ${ }^{2,7,8}$. A grande dificuldade neste aspecto era o emprego de toda sorte de misturas refrigerantes (água + gelo, gelo + sal de cozinha, gelo + cinzas, gelo + carvão, neve + álcool etílico, neve ou gelo em fusão...) e de vários sensores de temperatura (afora o álcool e o mercúrio, tem-se referência ao uso de alcatrão, óleo de linhaça e azeite de oliva). Assim, parece claro que determinar a "temperatura" de um corpo naquele tempo dependia do modo de cada um construir seu instrumento ${ }^{2,3,7,8,12-14}$.

Durante a década de 1660, Robert Hooke estabeleceu os primeiros princípios de comparação entre termômetros de diferentes construções, evitando assim a necessidade de construir réplicas exatas de cada modelo $0^{5,10,14}$. Em sua escala, um grau correspondia a uma variação equivalente a $0,2 \%$ do volume do líquido termométrico contido no instrumento. Por isso, apenas um ponto fixo era necessário, tendo escolhido a temperatura de fusão do gelo.

Em 1702, o astrônomo Ole Roemer (1644-1710), utilizando dois pontos fixos em sua escala (fusão do gelo e ebulição da água), deu início à criação de escalas termométricas que se assemelham às que se conhecem hoje em dia, e à construção de termômetros muito próximos aos modelos atuais ${ }^{2,5,8}$.

\section{Século XVIII: a profusão das escalas termométricas}

O uso sistemático de termômetros teve um início bastante difícil. Face a problemas culturais, de comunicação, guerras, diferentes interpretações do fenômeno da temperatura e diferentes maneiras de construir o instrumento, uma enorme quantidade de escalas termométricas foram propostas ao longo do século XVIII, situação que dificultava enormemente a comparação de resultados obtidos em um país e outro. Há referência a 27 escalas em uso na Europa em $1778 !^{5,12}$. Três delas difundiram-se no meio científico, sendo bastante usadas ao longo dos séculos XIX e XX.

A escala Réaumur $\left({ }^{\circ} \mathrm{R}\right)$, do francês René-Antoine F. de Réaumur (1683-1757) $)^{15}$ - em 1730, apresentou uma escala termométrica baseada na expansão térmica do álcool. Os pontos fixos eram o ponto de congelamento da água $\left(0^{\circ} \mathrm{R}\right)$, e o ponto de ebulição desta $\left(80^{\circ} \mathrm{R}\right)$. Esta escala fez muito sucesso na França e nos países sob sua influência cultural, sendo bastante usada até o início do século XX.

A escala Fahrenheit $\left({ }^{\circ} \mathrm{F}\right)$, devida ao alemão Daniel G. Fahrenheit (1686-1736) - após contatos mantidos com Roemer, Fahrenheit desenvolveu um termômetro de mercúrio (1714) de uso prático (menor tamanho), adotando também a prática de ferver o tubo para expulsar o ar do interior antes do fechamento do mesmo. Além disso, desenvolveu um método para limpar o mercúrio, de forma que não aderisse ao tubo de vidro. Na época, os termômetros feitos com álcool tornavam difícil medir altas temperaturas porque o ponto de ebulição do líquido é muito baixo $\left(78,3{ }^{\circ} \mathrm{C}\right)$. Os cientistas costumavam misturar água para compensar esse problema, mas a dilatação do material não era uniforme. Isso impedia que a escala do termômetro tivesse subdivisões pequenas. Essa era a grande vantagem do mercúrio sobre o álcool. Outra grande contribuição foi a criação de 
uma escala, utilizada até hoje nos países anglo-saxões, onde a temperatura de fusão do gelo à pressão de uma atmosfera está a $32{ }^{\circ} \mathrm{F}$ $\left(0{ }^{\circ} \mathrm{C}\right)$ e a de ebulição, a $212^{\circ} \mathrm{F}\left(100{ }^{\circ} \mathrm{C}\right)$. Para criar os pontos fixos de temperatura de sua escala, arbitrou a temperatura de uma mistura de água, gelo e sal (cloreto de amônio) como o ponto baixo $\left(0{ }^{\circ} \mathrm{F}\right) \mathrm{e}$ a temperatura do corpo humano como o ponto alto $\left(100{ }^{\circ} \mathrm{F}\right)$. O espaço entre os pontos foi dividido em 100 divisões. As pesquisas de Fahrenheit com termômetros confirmaram que cada líquido possuia um ponto de ebulição fixo e também que o ponto de ebulição varia com a pressão. O modelo de termômetro de Fahrenheit revolucionou o sistema de medidas termométricas, devido à sua precisão e reprodutibilidade ${ }^{3,8,10,13-15}$. Antes de 1714 , nenhuma escala era universalmente aceita. A escala de Fahrenheit ganhou popularidade, principalmente devido à reprodutibilidade e à qualidade de construção dos termômetros por ele produzidos.

A escala Celsius $\left({ }^{\circ} \mathrm{C}\right.$ ) é devida ao sueco Anders Celsius (17011744). Em 1742, publicou um artigo nos Anais da Academia Sueca de Ciências intitulado "Observações em duas persistentes escalas em um termômetro", que deu origem à sua escala termométrica. Usou o ponto de ebulição da água em uma extremidade ( 0 grau) e o de congelamento na outra (100 graus $)^{2,3,7}$. A inversão da escala tal como se usa hoje é motivo de controvérsias, mas talvez isso se deva a outro sueco, o médico Carl von Linné ou Carolus Linnaeus (1707-1778), que convenceu um fabricante de instrumentos científicos, Daniel Ekström (1711-1760), de que a inversão era mais conveniente para seu trabalho ${ }^{2,15}$.

Cabe salientar que, naquela época, a escala sempre se iniciava do zero, diferindo apenas sobre a posição desse zero segundo a mistura refrigerante usada. Ao que parece, buscava-se trabalhar com misturas refrigerantes as mais frias possíveis para aí se estabelecer o seu "zero", $2,5,7,8$.

Em 1794, definiu-se que o grau termométrico seria a centésima parte da distância entre as marcas correspondentes ao ponto de fusão do gelo e ao ponto de ebulição da água. Surgia assim a escala centígrada, a outra denominação da escala Celsius (até 1948, quando a IX Conferência Internacional de Pesos e Medidas mudou o nome para grau Celsius) $)^{5}$.

\section{Século XIX: o zero absoluto}

As moléculas de um gás estão em movimento desordenado, denominado agitação ou movimento térmico. Quanto mais intensa a agitação térmica das moléculas, maior será a energia cinética de cada uma e, em consequiência, maior a temperatura ${ }^{16,17}$. Assim, podese imaginar que a temperatura mais baixa que pode existir é um estado em que a agitação térmica cessa, isto é, em que as moléculas estão em repouso. A esse limite inferior de temperatura dá-se o nome de zero absoluto.

Baseado neste estado térmico William Thomson (1824-1907), mais tarde Lord Kelvin, estabeleceu, em 1848, a escala absoluta ${ }^{1,2}$. Kelvin verificou que a pressão de um gás diminuía de 1/273 do valor inicial quando resfriado a volume constante de $0 \mathrm{a}-1{ }^{\circ} \mathrm{C}$, concluiu que a pressão seria nula quando o gás estivesse a $-273{ }^{\circ} \mathrm{C}$. Como a pressão do gás é devida ao bombardeio das moléculas sobre as paredes do recipiente, no estado térmico de pressão nula, as moléculas do gás deveriam estar em repouso. Se a temperatura é uma medida do grau de agitação das moléculas, ela deve ser nula quando a agitação for nula. A escala absoluta criada por Kelvin tem origem (zero) no zero absoluto e adota como unidade o kelvin (símbolo K) cuja extensão, por definição, é igual à do grau Celsius $\left({ }^{\circ} \mathrm{C}\right)$. Comparando as indicações da escala Celsius e da escala proposta por Kelvin, para um mesmo estado térmico, nota-se que a temperatura absoluta é sempre 273,15 unidades mais alta que a temperatura Celsius correspondente.
Nessa discussão, passa-se por alto a questão do real estado físico do gás nas vizinhanças do zero absoluto. Contudo, baseado nos trabalhos de Nicolas L. S. Carnot (1796-1832), que idealizou um ciclo que proporcionaria rendimento máximo a uma máquina térmica (ciclo de Carnot), e cujo rendimento não depende da natureza do agente térmico utilizado na máquina (depende apenas das temperaturas absolutas das fontes quente e fria), é possível dar uma outra interpretação da escala absoluta de temperatura ${ }^{1,4,17}$.

Na máquina de Carnot, a grandeza termométrica é a quantidade de calor trocada com as fontes quente e fria. No ciclo de Carnot:

$Q_{1} / T_{1}=Q_{2} / T_{2}$

onde $Q_{1}$ é a quantidade de calor cedida pela fonte quente, $Q_{2}$ é a quantidade de calor não convertida em trabalho, $T_{1}$ é a temperatura da fonte quente e $T_{2}$ é a temperatura da fonte fria.

$\mathrm{O}$ rendimento de uma máquina de Carnot é dado por:

$\eta=1-\left(T_{2} / T_{1}\right)$

Se a temperatura da fonte fria $\left(T_{2}\right)$ for $0 \mathrm{~K}$, tem-se que $\eta=1(100 \%)$.

Portanto, o zero absoluto ou zero Kelvin $(0 \mathrm{~K})$ é a temperatura da fonte fria de uma máquina de Carnot que apresenta rendimento $100 \%(\eta=1)$. Nessa situação, a máquina térmica converte integralmente calor em trabalho, o que não é possível, não há como realizar essa conversão em um processo cíclico. Daí conclui-se que o zero absoluto é inatingível ${ }^{4,17}$. Apesar disso, pesquisas recentes ${ }^{18}$ empregando o condensado de Bose-Einstein permitiram atin-

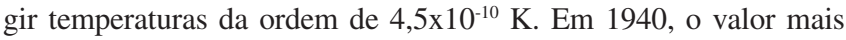
baixo atingido era $0,015 \mathrm{~K}^{11}$.

Além da escala absoluta proposta por Kelvin, existe outra idealizada por William J. M. Rankine (1820-1872), chamada de escala Rankine, hoje praticamente sem uso, e designada por R. A relação entre as duas escalas absolutas é $\mathrm{R}=1,8 \mathrm{~K}$.

$\mathrm{O}$ estabelecimento de um conceito de temperatura baseado em considerações distintas do sentido do tato representou um enorme avanço na Física, mas surpreende que o conceito do zero absoluto tenha passado por décadas na mais completa obscuridade. Compêndios da história da Física e livros didáticos do ensino secundário (atual médio) e superior editados no Brasil ou no exterior até os anos 1940 mal citavam a "existência" do zero absoluto. As menções encontradas pareciam enquadrá-lo como um conceito mais do campo filosófico que da física experimental propriamente dita. $\mathrm{O}$ avanço tecnológico da instrumentação da área da criogenia fez com que o trabalho a baixas temperaturas se tornasse viável. Exemplos da importância do trabalho a baixas temperaturas são a superfluidez do hélio e a supercondutividade de metais.

\section{Século XX: revisões e redefinições}

Termômetro legal - solução Giauque $e^{1,16}$

O termômetro legal é o termômetro de gás a volume constante, onde a grandeza termométrica é a pressão do gás. Ele é, por definição, o termômetro padrão. Os outros termômetros são aferidos em comparação a ele. Conforme a Figura 3, esse termômetro consiste de um recipiente A que contém o gás sob baixa pressão. A pressão do gás é medida através da altura $\mathrm{H}$ da coluna de mercúrio que preenche o manômetro $\mathrm{B}$. O volume do gás é mantido constante, mediante a movimentação vertical do reservatório $\mathrm{C}$ que contém mercúrio e que se comunica com a parte inferior do manômetro. $\mathrm{O}$ gás utilizado é geralmente hélio ou hidrogênio extremamente rarefeito (quase vácuo). Desse modo, a função termométrica é linear. 


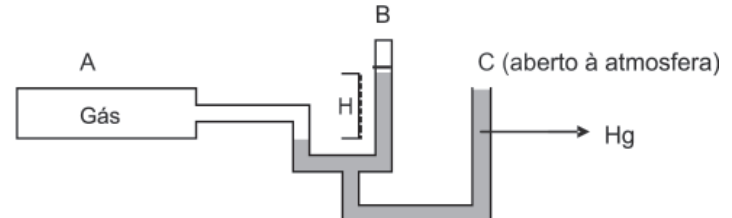

Figura 3. Esquema do termômetro de gás a volume constante: o volume é mantido constante pela movimentação do reservatório $C$. A cada temperatura corresponde uma altura $H$ de mercúrio

Existe um zero natural nessa função termométrica - é o ponto em que a pressão do gás ideal é nula (zero absoluto). Logo, apenas um outro ponto precisa ser definido para se estabelecer a função termométrica do termômetro legal.

Desde 1954, por proposta de William F. Giauque (1895-1982), Prêmio Nobel de Química em 1949, o ponto fixo adotado é o ponto triplo da água.

Seja $p_{T}$ a pressão que o gás do termômetro exerce na temperatura do ponto triplo da água e $p$ a pressão do gás que corresponde a uma temperatura $T$ qualquer. Como o gás sofre um processo isocórico, tem-se:

$p / p_{T}=T / T_{T}$

$T=T_{T}\left(p / p_{T}\right)$

$T=273,16\left(p / p_{T}\right)$

que constitui a função termométrica do termômetro legal, sendo $p_{T}$ um valor constante previamente determinado. O estabelecimento do ponto triplo da água como único ponto fixo para definir a escala do termômetro legal é conhecido como solução Giauque.

Uma célula de ponto triplo ou célula Giauque é mostrada na Figura 4. A célula é resfriada até que água, gelo, e vapor de água estejam em equilíbrio. A temperatura é $273,16 \mathrm{~K}$ por definição. Um termômetro pode ser calibrado inserindo-o no tubo central.

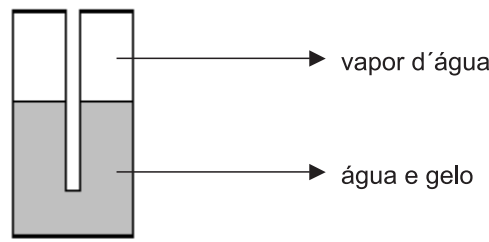

Figura 4. Descrição de uma célula de ponto triplo da água para calibração de termômetros

\section{Escala internacional de temperatura ${ }^{19,20}$}

Para se ter maior praticidade e precisão nas medidas de temperatura, foi criada uma escala baseada em fenômenos de mudança de estado físico de substâncias puras, que ocorrem em condições únicas de temperatura e pressão. São chamados de pontos fixos de temperatura. No início do século XX, constatou-se a necessidade de uma escala universal de temperatura definida de modo a ser precisa, reprodutível, simples de usar e que fornecesse valores de temperatura os mais próximos possíveis da temperatura termodinâmica. Chamou-se esta escala de IPTS - Escala Prática Internacional de Temperatura. A primeira escala prática internacional de temperatura somente surgiu em 1927, face à ocorrência da Primeira Guerra Mundial. Foi revista e modificada em 1948 (IPTS-48). Em 1960, mais modificações foram feitas e, em 1968, uma nova edição foi publicada (IPTS-68).

Desde 01/01/1990 está em vigor a ITS-90, que redefiniu al- guns pontos fixos de temperatura da IPTS-68, como visto na Tabela 1. Ela fora estabelecida três anos antes, na XVIII Conferência Geral de Pesos e Medidas.

A introdução dessa nova escala de temperaturas trouxe como conseqüência a modificação de muitos dos valores numéricos de temperatura, principalmente os mais precisos. Este aspecto pode ter algumas consequiências importantes para todos os que trabalham em áreas da ciência e da técnica onde são necessárias medições rigorosas da temperatura. Uma dada temperatura expressa com base na ITS-90 tem um valor numérico diferente daquele que tinha quando era expressa a partir da IPTS-68. Existem poucas exceções, como no caso do zero absoluto $(0 \mathrm{~K})$ e da temperatura do ponto triplo da água (273,16 K). A título de exemplo, o ponto de ebulição da água, à pressão atmosférica normal era de $100{ }^{\circ} \mathrm{C}$ pela IPTS-68, sendo agora $99,974{ }^{\circ} \mathrm{C}$. Diferenças como esta são detectadas em poucos laboratórios. Outras grandezas muito utilizadas nos vários domínios técnicos e científicos, que também são afetadas por estas alterações são a capacidade calorífica, a entalpia e a entropia ${ }^{20}$.

Tabela 1. Pontos Fixos estabelecidos na ITS-90, comparados aos valores fixados na IPTS-68

\begin{tabular}{lrr}
\hline PONTOS FIXOS & \multicolumn{1}{c}{ IPTS-68 } & \multicolumn{1}{c}{ ITS-90 } \\
\hline Ebulição do oxigênio & $-182,962{ }^{\circ} \mathrm{C}$ & $-182,954{ }^{\circ} \mathrm{C}$ \\
Ponto triplo da água & $+0,010^{\circ} \mathrm{C}$ & $+0,010^{\circ} \mathrm{C}$ \\
Solidificação do estanho & $+231,968^{\circ} \mathrm{C}$ & $+231,928^{\circ} \mathrm{C}$ \\
Solidificação do zinco & $+419,580{ }^{\circ} \mathrm{C}$ & $+419,527{ }^{\circ} \mathrm{C}$ \\
Solidificação da prata & $+961,930{ }^{\circ} \mathrm{C}$ & $+961,780{ }^{\circ} \mathrm{C}$ \\
Solidificação do ouro & $+1064,430{ }^{\circ} \mathrm{C}$ & $+1064,180^{\circ} \mathrm{C}$ \\
\hline
\end{tabular}

Definição da unidade SI de temperatura termodinâmica ${ }^{19,20}$

A medição das grandezas físicas requer a adoção de um sistema de unidades. Toda a moderna metrologia está baseada em um conjunto de definições constantes do "Système International d'Unités" (Sistema Internacional de Unidades), abreviadamente designado por SI. Neste sistema, a temperatura termodinâmica constitui uma das sete unidades ditas "de base", tendo por unidade o kelvin, o qual se encontra assim definido: "o kelvin, unidade de temperatura termodinâmica, é a fração 1/273,16 da temperatura termodinâmica do ponto triplo da água". Esta definição foi aprovada pela XIII Conferência Geral de Pesos e Medidas (CGPM) em 1967, sendo uma revisão da definição primeiramente introduzida em 1954.

O SI reconhece que os valores de temperatura expressos em kelvins nem sempre são adequados para o cotidiano. Assim, foi definido o grau Celsius, de acordo com a expressão $273,15+t /{ }^{\circ} \mathrm{C}$ $=T / \mathrm{K}$ em que $t$ é a temperatura termodinâmica em graus Celsius e $T$, a temperatura termodinâmica equivalente em kelvins.

\section{A EVOLUÇÃO DO TERMÔMETRO DE LÍQUIDO}

A análise dos mais de 500 termômetros existentes no acervo do Museu da Química Prof. Athos da Silveira Ramos (1906-2002), instalado no IQ/UFRJ, mostra que não houve mudança significativa no desenho desse instrumento ao longo de mais de 130 anos (comparar as Figuras 1 e 5). É verdade que o tamanho do mesmo pode variar segundo a finalidade à qual se destina (processos e experimentos em escala de bancada, piloto ou industrial), mas podese afirmar que o princípio de construção de termômetros que utilizam como grandeza termométrica a expansão térmica de um líquido não se modificou ao longo do tempo ${ }^{21-23}$. 


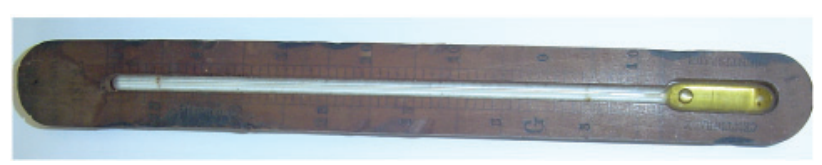

Figura 5. Termômetro a álcool (corante amarelo) na escala Celsius (1872). A escala $\left(-10 /+50^{\circ} \mathrm{C}\right)$ é gravada na madeira, onde se insere o tubo e o bulbo de vidro na cavidade central. Pertenceu à Escola Politécnica do Rio de Janeiro, atual Escola Politécnica da UFRJ

No que diz respeito à comparação com figuras de modelos anteriores à época abrangida pelo acervo em exame ${ }^{2-5,24}$, observa-se uma tendência à redução do tamanho do instrumento para uma mesma finalidade, resultando em aparelhos mais leves e fáceis de manusear, reduzindo o risco de quedas, acidentes e contaminação ambiental devido ao mercúrio. Existe também um outro aspecto relevante, que é a passagem da escala de fabricação artesanal para o modo de produção industrial. Nos Estados Unidos, a primeira empresa foi provavelmente instalada em $1820^{25}$ na cidade de Nova Iorque, enquanto que na Europa isso já ocorrera no final do século XVIII ${ }^{13}$.

Os termômetros de mercúrio são amplamente dominantes sobre os de álcool, estes últimos contendo escalas que nunca ultrapassavam $+50{ }^{\circ} \mathrm{C}\left(\mathrm{ou}+40{ }^{\circ} \mathrm{R}\right)$; isso porque os usos mais comuns em trabalhos experimentais e em práticas de ensino exigem aquecimento, situação em que o mercúrio tem maior faixa de temperatura de trabalho que o álcool.

Até por volta de 1920 a escala Réaumur era bastante freqüente nos termômetros, mesmo aqueles de origem não francesa (basicamente, alemã), sendo a partir daí suplantada pela escala Celsius. Apenas nos termômetros oriundos dos Estados Unidos e da Inglaterra é que se encontra a escala Fahrenheit.

Nessa mesma época passou a ser bastante comum a presença de jogos de termômetros de faixa estreita (Figura 6). Suas aplicações compreendem o controle de temperatura de banhos termostáticos, a determinação de propriedades físico-químicas (como viscosidade, tensão superficial e densidade), o controle de reações químicas e de procedimentos como a destilação.

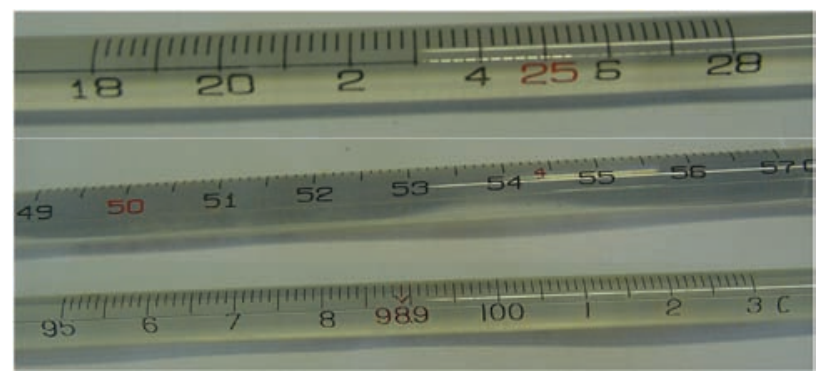

Figura 6. Exemplos de termômetros de faixa estreita, usados em viscosímetros, onde a quantidade de mercúrio é limitada e calculada para a escala diferencial desejada; existe uma expansão do tubo capilar antes de se chegar à escala, e outra como medida de segurança, caso o tubo fique superaquecido, evitando seu rompimento. Os bulbos são tanto maiores quanto maior a temperatura a ser medida em cada faixa. Todos são de procedência norte americana, anos 1960

\section{O termômetro associado a um densímetro}

Cerca de $60 \%$ do acervo examinado corresponde a instrumentos onde se associa um termômetro a um densímetro (aparelho flutuador que permite determinar densidades sem o auxílio da balança). Eles podem ser divididos em três partes: o bulbo de mercúrio + o elemento flutuador; um corpo cilíndrico onde se insere a escala de temperatura por meio de uma tira de papel inserida em seu interior e, uma haste cilíndrica concêntrica à parte anterior, mas de diâmetro menor, fechada na parte superior, onde se insere pela parte interna a escala de densidade (ou outra variável relacionada) impressa em uma tira de papel. Esta escala atravessa a superfície do líquido, de modo a permitir a leitura desejada. $\mathrm{O}$ instrumento era projetado para que se mantivesse na vertical ao longo de toda a faixa de trabalho (o centro de massa fica localizado na parte inferior do mesmo).

Talvez não seja de se admirar porque o termômetro-densímetro tornou-se, a partir do século XIX, um instrumento tão importante na indústria e no ensino. Em uma época em que a análise química ainda era incipiente, o emprego da determinação de propriedades físicas era extremamente importante para se caracterizar um dado material. Assim, grandezas como os pontos de fusão e de ebulição, o índice de refração, a densidade, a cor e outros parâmetros físico-químicos eram extremamente valiosos para os analistas. A associação do densímetro com o termômetro compreende-se facilmente visto que a densidade do líquido (resultado do quociente entre a massa do corpo considerado e o volume por ele ocupado) é dependente da temperatura. Essa situação vale também para líquidos contendo solutos dissolvidos, significando um meio de avaliação da concentração do soluto pela determinação da densidade da solução correspondente. Nesses casos é comum, em vez de se determinar a densidade do material, empregar uma escala de concentrações, obtida através de uma proporção, onde a cada densidade corresponde uma determinada concentração de soluto dissolvido. Isso tinha particular valor em processos industriais ${ }^{26}$. Os livros de "física industrial" (operações unitárias da indústria química) davam grande ênfase à temperatura e à densidade como meios de controle de processos, como atesta L. Vigreux (1854-1910), o mesmo idealizador da coluna de destilação que leva seu nome: "não se pode controlar processos unitários sem que se saiba manejar instrumentos de medida de propriedades físicas"27.

A praticidade do uso, o baixo custo e a leitura simultânea de dois parâmetros de grande importância prática responderam pela ampla aceitação do instrumento no mercado consumidor. Até hoje, particularmente nas indústrias fermentativas, o termômetrodensímetro desempenha papel primordial, sendo também bastante usado em experimentos de físico-química e no preparo de soluções de ácidos e hidróxido de amônio, a partir da avaliação da concentração do material de partida por meio do referido instrumento.

No caso de soluções existem vários tipos de instrumentos: acidímetros (densidade de soluções de ácidos como clorídrico, fosfórico, nítrico, etc), sacarímetros (soluções de sacarose), alcoolímetros (soluções de etanol) e salímetros (densidade de sais dissolvidos), os quais representam quase todo o universo de instrumentos deste tipo existentes no acervo em exame.

A forma de expressão das concentrações depende do soluto: para os acidímetros e salímetros, o resultado era expresso em termos de $\% \mathrm{~m} / \mathrm{m}(\mathrm{p} / \mathrm{p})$ ou em vol/vol; as concentrações de etanol podiam também ser expressas em ${ }^{\circ}$ Gay-Lussac (muito comum), ${ }^{\circ}$ Baumé e ${ }^{\circ}$ Tralles (nos modelos anteriores a 1900); as de sacarose podiam ser medidas em ${ }^{\circ}$ Brix. Os valores de leitura podiam ser tanto em intervalos estreitos (por ex., 1-10\% m/m), como em uma faixa bem ampla (por ex., $0-100 \% \mathrm{~m} / \mathrm{m}$ ), segundo a precisão necessária. Para o caso dos líquidos puros e de algumas soluções, os valores eram expressos em valores de densidade $\left(\mathrm{g} \mathrm{cm}^{-3}, \mathrm{~g} \mathrm{~mL}^{-1}\right.$ ou ainda em valores de densidade relativa à água a $\left.4{ }^{\circ} \mathrm{C}, 1 \mathrm{~g} \mathrm{~cm}^{-3}\right)$.

Mesmo nos modelos mais antigos, encontra-se marcada à escala uma temperatura de referência em que o aparelho foi calibrado (normalmente, 15 ou $20^{\circ} \mathrm{C}, 12$ ou $16^{\circ} \mathrm{R}$ ) e os fatores de correção caso se empregasse o instrumento fora desta referência.

As Figuras 7 a 11 mostram exemplos representativos de termômetros-densímetros empregados em mais de um século. É digno de menção que, mesmo decorridos mais de 100 anos, todos os ins- 
trumentos continuam funcionando corretamente, fato admirável, levando-se em conta a delicada tarefa da correta colocação das escalas de temperatura e concentração (ou densidade) dentro do instrumento; isto demonstra sua robustez e durabilidade.

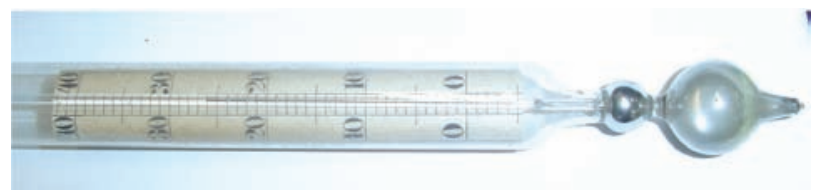

Figura 7. Parte de um termômetro $\left({ }^{\circ} \mathrm{C}\right)$ - sacarímetro $(0-10 \% \mathrm{~m} / \mathrm{m}), 1892$. Naquela época, o próprio mercúrio era o elemento de equilíbrio do instrumento. Fabricado na Alemanha

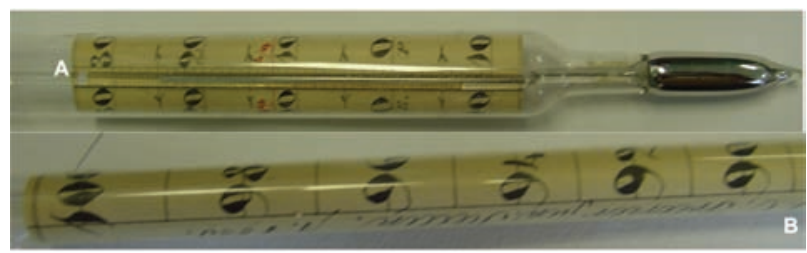

Figura 8. Termômetro $\left({ }^{\circ} R, a\right)$ - alcoolímetro $(40-100 \% v / v, b), 1885$. Fabricado na Alemanha

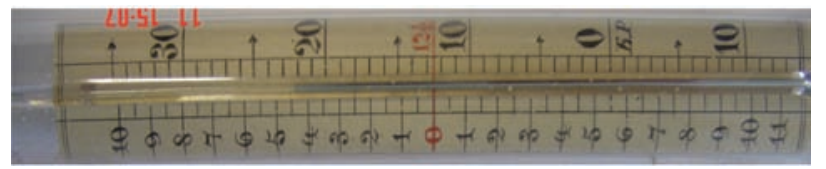

Figura 9. Termômetro $\left({ }^{\circ} R\right)$-alcoolímetro $\left(0-100^{\circ}\right.$ Tralles). Notar a presença de uma temperatura de referência $\left(12,5^{\circ} \mathrm{R}-\right.$ em vermelho) e a curva de calibração para o caso de emprego em outras temperaturas. Procedência alemã, início do século $X X$

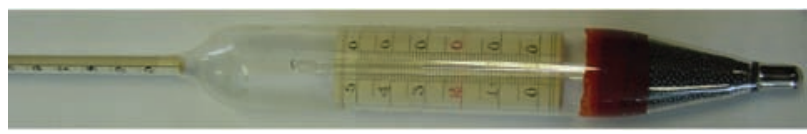

Figura 10. Sacarímetro (40-60 ${ }^{\circ}$ Brix) - termômetro na escala Celsius (1962). Feito nos Estados Unidos. Observa-se aqui uma importante mudança na construção do instrumento: a substituição, por volta de 1920, do mercúrio pela bolinha de chumbo como elemento de equilíbrio. As bolinhas, inicialmente soltas, passaram mais tarde a serem imobilizadas com resina

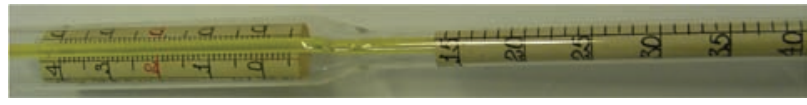

Figura 11. Densímetro para lactose (1960), raro modelo onde a escala de temperatura $\left({ }^{\circ} \mathrm{C}\right)$ se situa acima da de concentração da lactose $\left(15-40 \mathrm{~g} \mathrm{~mL}^{-1}\right)$, por conta da opacidade do leite. Fabricado nos Estados Unidos

\section{O TERMÔMETRO ELETRÔNICO}

As primeiras versões surgiram na década de $1970^{28}$, acompanhando a tendência notada em outros instrumentos de medida. Os termômetros eletrônicos são sérios candidatos a substituir os termômetros de mercúrio. Apesar da ampla utilização destes nos últimos 300 anos, os problemas ambientais ligados a esse elemento químico fazem com que tendam a desaparecer dos laboratórios com a evolução do instrumental eletrônico de medição da temperatura, a qual busca substituir o metal no que for possível.
Não é objetivo detalhar o funcionamento destes instrumentos, mas é importante mencionar que um termômetro eletrônico tem seu princípio de funcionamento baseado em sensores elétricos, como termopares, termômetros de resistência e termístores (resistores que apresentam grande variação da resistência em função da variação da temperatura ${ }^{29}$ ), além da radiação infra-vermelha, versão que não exige contato físico entre o termômetro e o objeto cuja temperatura se deseja medir. A resposta desses sensores à temperatura é uma função não linear. Para converter a resposta do sensor em um sinal elétrico linearmente relacionado à temperatura é necessária alguma forma de linearização ${ }^{22,30}$ (segmentada, analógica e microprocessada, a mais precisa). Nos últimos tempos, a leitura analógica do sinal vem sendo substituída pela digital, mais cômoda e atualmente até mais barata.

Os termômetros eletrônicos podem operar de -273 a $1200{ }^{\circ} \mathrm{C}$. Tanto a faixa de operação quanto os limites de erro dependem bastante do sensor utilizado. Uma das principais aplicações é como padrão de temperatura para as calibrações industriais, dada a praticidade de uso (portabilidade e indicação visual da temperatura). Para essa aplicação, o termômetro deve apresentar boa estabilidade temporal (leitura constante com o tempo). Para a correta especificação do modelo, além da temperatura a ser medida, devese comparar a tolerância da medição que se pretende fazer com as especificações do termômetro.

Um modelo eletrônico apresenta várias vantagens ${ }^{29}$ : baixo peso, baixo custo, rápida resposta a mudanças de temperatura, boa resistência mecânica e eliminação do erro inerente ao ser humano quando da leitura da temperatura em um termômetro convencional (erro de paralaxe, regressão da coluna de mercúrio, tempo de leitura lento $\left.^{30}\right)$. Na medicina, este instrumento apresenta precisão da ordem de um décimo de grau e requer apenas cerca de um décimo do tempo necessário para tomar a temperatura do paciente em relação ao termômetro clínico clássico. Além desses empregos, deve-se destacar o uso crescente em objetos de decoração e funcionais, como materiais de escritório em geral, quadros, relógios e letreiros luminosos em locais públicos. Isso se deve à possibilidade de fabricar sensores de tamanhos variados, o que permite sua inserção em toda uma variedade de objetos.

Além dos recursos eletrônicos, ainda podem ser encontrados os seguintes itens: presença de comando liga-desliga; ajuste de zero (calibração contra outro termômetro) e um circuito conversor nas escalas Celsius e Fahrenheit (mostrador multifuncional).

\section{A RELAÇÃO DA TEMPERATURA COM A QUÍMICA - A TERMOQUÍMICA}

A partir do momento em que a temperatura passou a ser determinada com precisão satisfatória, várias grandezas físico-químicas ganharam um importante significado prático no desenvolvimento da Física e da Química a partir do final do século XVIII. Conceitos como calor específico, calores latentes de fusão e de vaporização, condutividade térmica, etc foram estabelecidos e ganharam metodologias práticas de medida, inviáveis se a termometria não tivesse atingido o grau de desenvolvimento verificado a partir da época de Fahrenheit.

A rigor, todos os processos físicos e químicos envolvem liberação ou absorção de energia. Os aparelhos destinados a medir as variações de energia nos diversos processos são chamados calorímetros, e a metodologia é denominada calorimetria ${ }^{2,30,31}$. Existe um trabalho interessante que detalha o princípio e a versatilidade do calorímetro ${ }^{32}$. A unidade de calor foi tomada como sendo a quantidade necessária para aquecer de um grau, um grama de água, segundo Dulong (1785-1838). Parece que o nome caloria foi dado 
pela primeira vez por Fabre et Silbermann (1806-1865), em 1852, difundindo-se lentamente no meio científico ${ }^{2-4,17,33-35}$.

A temperatura manifesta-se das mais variadas formas e nos mais variados campos de aplicação da Química. Contudo, estritamente falando, o interesse recai na relação direta e natural entre ambas, o que ocorre através da termoquímica, a qual descreve os efeitos térmicos que se observam nas reações químicas. Esse elo tem razões históricas, principalmente devido ao grande interesse no fenômeno da combustão ${ }^{2-4}$, sendo explicitada em inúmeros livros de Química e de Física publicados até as primeiras décadas do século XX.

Quando a queima de um corpo foi reconhecida como uma reação química, tentou-se determinar a relação entre os fenômenos químicos e o calor. O. de Guericke (1602-1686) demonstrou que a chama "extrai do ar uma matéria" e Robert Boyle constatou que a "calcificação" do chumbo removia componentes do ar. Quando Antoine L. Lavosier (1743-1794) determinou que essa substância era o oxigênio e o calor era liberado devido a uma combinação química, passou-se a ter grande interesse em medir o calor produzido na combustão $0^{4,8,36}$.

Naqueles tempos, a medida de calor de combustão servia unicamente como medida de absorção de $\mathrm{O}_{2}$ do ar (combustão = oxidação = entrada de $\left.\mathrm{O}_{2}\right)^{4}$. Contudo, Hervard (1772-1867) observou que a decomposição do peróxido de hidrogênio liberava $\mathrm{O}_{2}$ e energia. Dulong observou que a queima de carbono em óxido nitroso era mais exotérmica que no ar. Isto exigia estudos bem mais cuidadosos que uma simples aplicação prática e empírica de um método ou de um conceito ${ }^{36}$. As aplicações iniciais da combustão eram mais de natureza empírica que propriamente teórica, sendo o desenvolvimento da máquina a vapor, peça-chave na I Revolução Industrial, um notável exemplo representativo ${ }^{2,3}$.

A importância da temperatura na Química se acha bem destacada no princípio publicado por Henry-Louis Le Chatelier (18501936), em 1888: ela tem um papel primordial na previsão do equilíbrio químico de uma reação reversível. Um aumento do aquecimento leva a reação no sentido contrário ao da liberação de energia (sentido endotérmico da reação). Muito do misticismo e do mistério que envolvia o comportamento de certos sistemas reacionais passou a ser explicado após os trabalhos de Le Chatelier ${ }^{36}$.

\section{CONCLUSÕES}

O termômetro, apesar de amplamente difundido e de ser hoje um instrumento de excepcional versatilidade na indústria, na ciência e no cotidiano, mostrou uma evolução histórica bastante lenta, por conta do empirismo que envolvia o calor e os fenômenos a ele relacionados, além do individualismo de cada um tratar a temperatura a seu modo. Somente quando se conseguiu fabricar instrumentos reprodutíveis e confiáveis, e estabelecer escalas termométricas de uso prático, é que o termômetro se impôs como um item essencial em laboratórios científicos. Em particular, o estabelecimento de um conceito de temperatura baseada em considerações termodinâmicas (levando à definição do zero absoluto), no século XIX, foi um avanço extraordinário frente ao estabelecimento de escalas termométricas baseadas em pontos arbitrários.

A evolução da Física e da Ciência em geral valorizou o emprego do termômetro na caracterização e na determinação de um número crescente de parâmetros físicos, químicos, biológicos, etc transformando-o em um item básico indispensável para a área de ensino e para o segmento industrial ${ }^{37}$.

A evolução técnica do instrumento passou pela redução de sua massa, correspondendo ao emprego de modelos menores; pela as- sociação com outros instrumentos cujos parâmetros avaliados são dependentes da temperatura (como no caso da densidade); pela redução das escalas termométricas hoje em uso; pela diversificação dos tipos de termômetro e de suas aplicações práticas ${ }^{13,14,37}$ e, pela substituição dos modelos baseados na dilatação de um fluido termométrico pelos termômetros eletrônicos. Neste particular, o termômetro é apenas um dentre tantos exemplos onde a digitalização revolucionou o formato e a aplicabilidade dos instrumentos.

\section{REFERÊNCIAS}

1. Faucher, R.; Physique, Hatier: Paris, 1966; Fuchs, W. R.; Física Moderna, São Paulo: Polígono, 1972.

2. Hoppe, E.; Histoire de la Physique, Payot: Paris, 1928.

3. Volkringer, H.; Les Etapes de la Physique, Gauthier-Villards: Paris, 1929.

4. Macedo, H. C. M.; Físico-Química I, Guanabara Dois: Rio de Janeiro, 1981.

5. http://www.help-temperatura.com.br/html/interesse/files/ HistoriaMedicaoTemperatura.pdf, acessada em Janeiro 2005.

6. Chagas, A. P.; Termodinâmica Química, Ed. UNICAMP: Campinas, 1999.

7. Tillreux, J.; Traité Élementaire de Physique, Cr. Berenger: Paris, 1925.

8. Murani, O.; Trattato Elementare de Fisica, U. Hoelpi: Milão, 1925.

9. Malta, C. F.; Compêndio de Physica Elementar e de Chimica Geral, Jornal do Commercio: Rio de Janeiro, 1928.

10. Lourenço, O. B.; Física - Iniciação ao Estudo da Física Experimental, Cia. Ed. Nacional: São Paulo, 1936.

11. Freitas, A.; Curso de Física, Cia. Melhoramentos: São Paulo, 1941.

12. http://www.termometro.com.br, acessada em Abril 2005.

13. Barnett, M. K.; J. Chem. Educ. 1941, 18, 358.

14. Brown, E. N.; J. Chem. Educ. 1934, 11, 448.

15. Davis, B.; New Practical Physics, The Macmillan Co: Nova Iorque, 1929.

16. Rice, O. K.; Critical Phenomena of Thermodynamics and Physics of Matter, Princeton, Univ. Press, 1955.

17. Reid, R. C.; Prausnitz, J. M.; Sherwood, T. K.; The Properties of Gases and Liquids, $3^{\text {rd }}$ ed., Mc Graw-Hill: Nova Iorque, 1977.

18. Leanhardt, A.; Pasquini, T. A.; Saba, M.; Schirotzek, A.; Shin, Y.; Kielpinski, D.; Pritchard, D. E.; Ketterle, W.; Science 2003, 301, 1513.

19. Preston-Thomas, H.; Metrologia 1990, 27, 1; Goldberg, R. N.; Weir, R. D.; Pure Appl. Chem. 1992, 64, 10.

20. Mangum, B. W.; Furukawa, G. T.; Guidelines for Realising the International Temperature Scale of 1990 (ITS-90), NIST Technical Note 1265, 1990.

21. Guillaume, C.; Traité Pratique de la Thermométrie de Précision, Gauthiard et Fils: Paris, 1889.

22. Michalski, L.; Eckersdorf, K.; McGee, J.; Temperature Measurement, $2^{\text {nd }}$ ed., John Wiley \& Sons: Nova Iorque, 2001.

23. Oliver, S. P.; Dictionary of National Biography, Londres, 1937, vol. XIV, p. $473-475$.

24. Bolton, H. C.; Evolution of the Thermometer, 1592-1743, The Chemical Publishing Co: Easton, 1900.

25. http://www.classicautomation.com/Automation/Taylor_Heritage.htm, acessada em Março 2005.

26. Joannis, A.; Encyclopédie Industrielle - Traité de Chimie Organique Appliquée, Gauthier-Villards et Fils: Paris, 1896, vol. 2.

27. Vigreux, L.; Traité Théorique et Pratique de Physique Industrielle, E. Bernard et Cie: Paris, 1893, vol. 1.

28. http://www.texto.de/Es/es/site/company/testory/17.jsp, acessada em Maio 2004.

29. Oliveira, W. A.; Quim. Nova 1978, 1, 5.

30. McGee, T. D.; Principles and Methods of Temperature Measurement, John Wiley \& Sons: Nova Iorque, 1988.

31. Simoni, J. A.; Jorge, R. A.; Quim. Nova 1990, 13, 108.

32. Chagas, A. P.; Quim. Nova 1992, 15, 94; Simoni, J. A.; Quim. Nova 1989, 12,376 .

33. Boyer, C. B.; Am. J. Physiol. 1942, 10, 176.

34. Taylor, S. F.; Ann. Sci. 1942, 5, 129.

35. Vollmann, R.; Discovery 1959, 20, 378.

36. Fraser, C. G.; The Story of Physics, Reinhold Publishing Co.: Nova Iorque, 1948.

37. Médrad, L.; Tochoiri, H.; Histoire de la Thermochimie, Publications de L'Université de Provence: Aix-en-Provence, 1994. 